\title{
Penile Cutaneous Horn
}

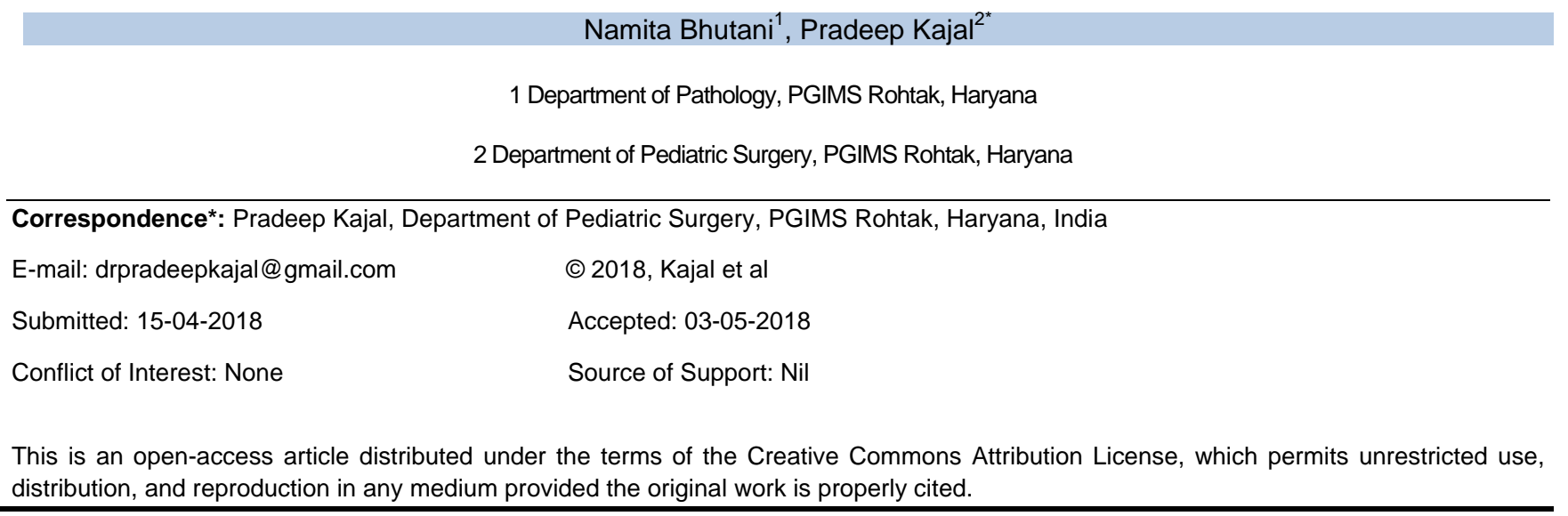

\section{DEAR SIR}

Cutaneous horn (cornu cutaneum) is a rare lesion consisting of a projectile, conical, dense, hyperkeratotic nodule which resembles the horn of an animal.[1] These occur mostly in sun-exposed parts and are typically found on the face and the scalp, but may also occur on the hands, eyelids, nose, chest, neck, shoulder and penis.[2] The horn is composed of compact keratin. Although the cutaneous horn may develop over a normal skin, these more often develop over some preexisting skin conditions like warts, keratosis, naevi, trauma, burns, lupus vulgaris, and even on an epithelioma.[3] Their occurrence on the penis is extremely uncommon. We report a case of cutaneous horn on penis.

A 9-year-old boy presented with conical shaped hard swelling over ventral surface of penis. He had noticed the lesion two months ago. The lesion gradually increased in size. Physical examination revealed a $2.5 \times$ $1 \mathrm{~cm}$, conical, curved, white lesion hard in consistency projecting outward from the left side of ventral surface of penis (Figure 1). There was no palpable inguinal lymphadenopathy. Biochemical, serological and radiological investigations were within normal limits. His systemic examination was unremarkable. A clinical diagnosis of penile cutaneous horn was made and surgical excision of the growth with a rim of normal glandular tissue around the base was performed and primary closure was achieved. The specimen was sent for histopathological examination. Histopathological findings were marked orthokeratotic type of hyperkeratosis, parakeratosis, acanthosis with prominent granular layer and papillomatosis of the epidermis. Basal layer was characterised by sporadically elongated rete ridges with the signs of incipient keratinisation and few mitotic figures. Subepithelial tissue showed foci of lymphoplasmacytic infiltration and capillaries of different shapes and size lined by endothelial cells. There was no evidence of dysplasia or malignancy. The child had normal postoperative recovery and doing fine on followup.

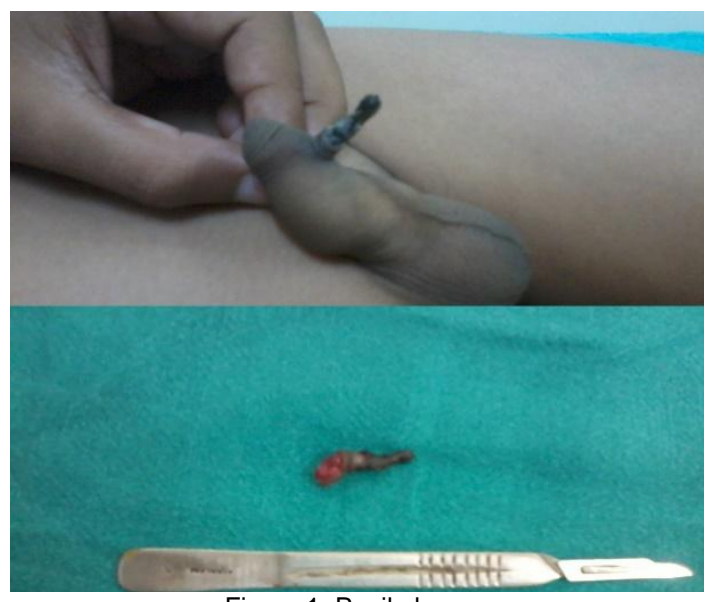

Figure 1: Penile horn. 
The term "cutaneous horn" is not a true diagnosis. It is named after the morphologic appearance to the animal horn. Its etiology is still unclear. The role of chronic irritation, phimosis, surgical trauma, and radiotherapy has been implicated in penile horn formation.[1]

The disease may be benign in $42 \%-56 \%$, premalignant in $22 \%-37 \%$, or frankly malignant in $20 \%-22 \%$ of patients. The European Association of Urology (EAU) guidelines on penile cancer report three categories of premalignant lesions, each with different probability of developing into SCC (Squamous cell carcinoma) of the penis: lesions sporadically associated with SCC of the penis (cutaneous horn of the penis and Bowenoid papulosis); lesions at an intermediate risk of progression to SCC (balanitis xerotica obliterans); and lesions at a high risk of developing into SCC of the penis (penile intraepithelial neoplasia occurring as Bowen's disease or erythroplasia de Queyrat).[4,5] Malignant change should be suspected in a rapidly growing lesion. On physical examination, these lesions consist of a compact, tapered, keratinous mass surrounding a warty base. Histopathological examination, especially at the base of the lesion, is necessary to rule out associated malignancy. Various lesions seen at the base of a cutaneous horn include squamous cell carcinoma, actinic keratosis, keratoacanthoma, Bowen's disease, seborrheic keratosis, basal cell carcinoma, hemangioma, keratotic and mucinous pseudopapillomatous balanitis, Kaposi's sarcoma, sebaceous adenoma and Paget's disease. In the index case no malignancy was identified at the base of horn.

Treatment includes wide surgical excision with careful histological examination to exclude a focus of malignancy. Since about one-third of penile cutaneous horns are associated with underlying malignancy an early excision is advised. If malignancy is present in a penile cutaneous horn, the treatment involves partial penectomy with or without regional lymph node dissection. Alternative approaches with carbon dioxide or neodymium YAG laser therapy may reasonably produce a lesser degree of scarring and a superior cosmetic result.[5]

Consent Statement: Authors declared that they have taken informed written consent, for publication of this report along with clinical photographs/material, from the legal guardian of the patient with an understanding that every effort will be made to conceal the identity of the patient however it cannot be guaranteed.

Author's Contributions: All authors contributed equally in concept, design, literature review, drafting the manuscript, and approval of the final manuscript.

\section{REFERENCES}

1. Copcu E, Sivrioglu N, Culhaci N. Cutaneous horns: are these lesions as innocent as they seem to be? World $\mathrm{J}$ Surg Oncol. 2004; 2:18.

2. Vera-Donoso CD, Lujan S, Gomez L, Ruiz JL, Jimenez Cruz JF. Cutaneous horn in glans penis: a new clinical case. Scand J Urol Nephrol. 2009; 43:92-3.

3. Rubin MA, Kleter B, Zhou M, Ayala G, Cubilla AL, Quint WG, et al. Detection and typing of human papillomavirus DNA in penile carcinoma: evidence for multiple independent pathways of penile carcinogenesis. Am J Pathol. 2001; 159:1211-8.

4. Mokos I, Mokos ZB, Ljubojević S, Corić M, Grce M, Michal $M$. Penile cutaneous horn ten years after treatment of verrucous squamous cell carcinoma on penile glans: Case report. Acta Dermatovenerol Croat. 2012; 20:30-3.

5. Pizzocaro G, Algaba F, Horenblas S. Solsona E, Tana S, Van Der Poel H, et al. Penile cancer guidelines 2009. Eur Urol. 2010; 57:1002-12.. 